Jurnal Manajemen dan Bisnis, Volume 2, No. 2, Januari 2021

\title{
PENGENDALIAN INTERNAL UNTUK PROSEDUR PENGELOLAAN SURAT MENYURAT DI SUB BAGIAN UMUM DAN KEPEGAWAIAN (UMPEG) DINAS PARIWISATA KEPEMUDAAN DAN OLAHRAGA KABUPATEN MAGELANG
}

\author{
Annisa Nur Salsabila ${ }^{1}$, Ghina Fitri Ariesta Susilo ${ }^{2}$ \\ Universitas Tidar
}

\begin{abstract}
This study is analyzing internal control for mail management procedures. This type of research is a qualitative approach. Data collection use the observation method and the interview method. The object of research is Dinas Pariwisata Kepemudaan dan Olahraga Kabupaten Magelang. The results showed that the control in the Sub Bagian UMPEG must to be improved. Low communication and coordination are obstacles in the management of letters and the distribution of letters to the concerned section. These problems can be overcome by examining again in the recording and distribution of letters.
\end{abstract}

Keywords: Internal control, Letter management procedure, Sub Bagian UMPEG Dinas Pariwisata Kepemudaan dan Olahraga Kabupaten Magelang

\begin{abstract}
ABSTRAK
Penelitian ini menganalisis pengendalian internal untuk prosedur pengelolaan surat menyurat. Jenis penelitian ini adalah pendekatan kualitatif. Pengumpulan data menggunakan metode obervasi dan metode wawancara. Objek penelitian adalah Dinas Pariwisata Kepemudaan dan Olahraga Kabupaten Magelang. Hasil penelitian menunjukkan bahwa pengendalian pada Sub Bagian UMPEG masih harus ditingkatkan. Kurangnya komunikasi dan koordinasi antar bidang merupakan kendala dalam pengelolaan surat dan pendistribusian surat kepada bidang yang bersangkutan. Kendala tersebut diatasi dengan lebih teliti lagi dalam pencatatan dan distribusi surat.
\end{abstract}

Kata-kata Kunci: Pengendalian internal, Prosedur pengelolaan surat menyurat, Sub Bagian Umum dan Kepegawaian Dinas Pariwisata Kepemudaan dan Olahraga Kabupaten Magelang

Korespondensi: Annisa Nur Salsabila. Universitas Tidar. Jalan Sudiro no 34 Dampit Mertoyudan Kabupaten Magelang Kode Pos: 56172. Email: annisansalsabila06@gmail.com 
Jurnal Manajemen dan Bisnis, Volume 2, No. 2, Januari 2021

\section{PENDAHULUAN}

Setiap organisasi membutuhkan pengarahan dan pengawasan untuk mencapai tujuan, karena organisasi merupakan bentuk kerja sama para anggota dalam melaksanakan serangkaian kegiatan demi tercapainya tujuan organisasi. Tujuan organisasi tersebut harus memiliki komunikasi yang efektif antar anggota. Komunikasi akan efektif jika proses penyampaian informasi juga cepat. Komunikasi dapat dilakukan secara langsung atau dengan berbagai media elektronik. Penyampaian informasi yang baik akan memperlancar proses kegiatan organisasi.

Surat merupakan sarana penyampaian informasi dalam suatu organisasi. Menurut Ridha \& Istiqomah (2019), peranan surat dalam organisasi perusahaan/instansi, menjadi bukti tertulis atas suatu informasi yang disampaikan atau kegiatan yang ditandai dengan adanya tanda tangan pejabat berwenang dan stempel perusahaan. Suatu organisasi yang melakukan kegiatan kedinasan sering dihadapkan pada persoalan dalam surat menyurat. Dalam organisasi pemerintah, surat mempunyai nilai penting, baik sebagai media komunikasi, sumber informasi dan dijadikan dinamika organisasi. Pengelolaan surat yang belum serius merupakan salah satu faktor rendahnya kualitas pengendalian internal. Surat yang dikelola masih kurang adanya komunikasi dan penyampaian informasi yang jelas antara pengelola surat dengan bagian yang bersangkutan. Pengelolaan yang baik harus ditentukan dalam prosedur yang telah diatur oleh suatu organisasi pemerintahan.

Prosedur membantu proses dalam usaha meningkatkan produktivitas kerja. Prosedur pengelolaan yang berjalan dengan baik menunjukkan sistem pengendalian intern suatu entitas berjalan dengan efektif. Pengendalian intern merupakan faktor penting bagi lembaga pemerintahan untuk mengetahui kualitas kerja serta menilai kinerja pegawai dalam melaksanakan tanggung jawabnya. Untuk membantu individu mengelola kinerjanya yaitu dengan peenilaian kerja yang dilihat dari berbagai sudut pandang penilaian tergantung pada tujuan organisasi (Halim, 2014).

Pengendalian internal pada Sub Bagian UMPEG masih kurang karena diketahui adanya kendala dalam penyampaian informasi antar bagian khususnya pada Sub Bagian Umum dan Kepegawaian (UMPEG). Pengendalian intern diperlukan untuk mengarahkan dan mengawasi tata kelola pada suatu organisasi pemerintahan. Adanya kendala atau hambatan mengakibatkan adanya kelemahan dalam sistem pengendalian internal. Tata kelola pemerintahan menunjukkan sistem pengedalian internal pada suatu organisasi.

Studi sebelumnya tentang pengelolaan surat, Hakim\&Mardiyah (2017) menjelaskan bahwa dalam pengelolaan surat membutuhkan adanya ketelitian dan juga dikerjakan dengan 
Jurnal Manajemen dan Bisnis, Volume 2, No. 2, Januari 2021

mengikuti prosedur. Pengelolaan surat merupakan salah satu tupoksi dan tanggung jawab Sub Bagian UMPEG. Permasalahan yang sering terjadi adalah kurangnya informasi yang rinci dalam penyampaian surat ke bidang-bidang yang dituju. Bidang bidang tersebut meliputi Bidang Destinasi, Bidang Kepemudaan, Bidang Keolahragaan, dan bidang TIC (Tourist International Center). Seiring dengan aktivitas di kantor dinas, maka perlu adanya kelancaran dan keberhasilan suatu program kerja atau kegiatan. Perlu adanya hubungan kerjasama yang baik antara lingkungan internal dan lingkungan eksternal. Hubungan kerjasama dilakukan untuk menyampaikan maksud dan tujuan tertentu dengan menggunakan surat.

Penyempurnaan tata kelola surat menjadi nilai penting agar berbagai informasi yang diterima tersampaikan dengan tepat dan sesuai dengan yang seharusnya ditujukan. Prosedur pengelolaan surat menyurat perlu diterapkan pada organisasi pemerintahan karena surat merupakan sumber informasi yang bermanfaat bagi terlaksananya kegiatan organisasi. Penelitian ini bertujuan untuk menganalisis pengendalian untuk prosedur pengelolaan surat menyurat di Sub Bagian UMPEG Dinas Pariwisata Kepemudaan dan Olahraga. Mengetahui lebih jelas kendala, dan bagaimana kebijakan dalam mengatasi kendala pada Sub Bagian UMPEG Dinas Pariwisata Pariwisata Kepemudaan dan Olahraga

\section{LITERATURE REVIEW}

Menurut Widjajanto (2001), pengendalian internal merupakan bentuk pengendalian, meliputi struktur organisasi dengan metode yang diterapkan dan ukuran untuk mengamankan aktiva, mengecek kecermatan dan ketelitian, meningkatkan efisiensi serta mendorong agar kebijakan manajemen untuk dipatuhi segenap organisasi.

Penerapan pengendalian internal sebagai bentuk kewajiban suatu entitas atau lembaga pemerintahan. Sistem suatu pengendalian internal adalah struktur pada organisasi yang didalamnya berisi pemisahan fungsi, sistem wewenang, prosedur, dan praktek yang sehat, mutu karyawan sesuai tanggung jawab anggotanya (Mukaromah, Nuraina, \& Suswandari, 2013).

Menurut Marjo (2000), surat adalah bentuk komunikasi tertulis sebagai sarana yang penyampaian suatu pernyataan atau informasi tertulis dari satu pihak kepada pihak lain. Pendapat lain menjelaskan pengertian surat adalah suatu komunikasi penyampaian informasi tertulis yang komunikasi tersebut berkaitan dengan bisnis atau nonbisnis dari satu pihak ke pihak lainnya (Purwanto, 2006). Surat berfungsi sebagai penyampaian pesan atau informasi tertulis serta berperan dalam pencapaian tujuan dalam kerjasama antar organisasi (Sitohang, 2018).

Surat Dinas menurut Sutarto (1983) adalah warkat yang berisi informasi resmi yang dibuat 
Jurnal Manajemen dan Bisnis, Volume 2, No. 2, Januari 2021

oleh pejabat yang berupa informasi pemberitahuan, pernyataan, dan pertanyaan untuk ditujukan kepada suatu pihak. Surat dinas merupakan bentuk komunikasi tertulis yang menyangkut kepentingan kegiatan organisasi atau kantor (Sedarmayanti, 2003). Surat dinas sebagai alat komunikasi tertulis yang berisi informasi resmi mengenai kegiatan kedinasan.

Surat masuk adalah surat yang diterima baik dari individu maupun instansi, dengan menggunakan buku pengiriman (ekspedisi) (Wursanto, 1991). Surat masuk merupakan surat yang diterima perusahaan atau lembaga pemerintahan baik itu perorangan maupun perusahaan atau lembaga pemerintahan. Surat yang masuk dan diterima oleh bagian penerima surat akan disampaikan kepada bagian yang bersangkutan dengan prosedur yang sudah ditetapkan. Bagian surat bertugas dalam pengelolaan, pencatat, pengarah, dan pengolah surat. Dalam suatu instansi kedinasan, pengelolaan surat dilakukan oleh sub bagian umum. Menurut Widjaja (1990) penerima surat bertugas sebagai berikut: (1) Penerimaan surat, (2) Pemeriksaan jumlah, (3) Pemeriksaan alamat surat, (4) Pemberian paraf serta nama pada catatan buku ekspedisi, (5) Pengecekan atau meneliti kerahasiaan, kesesuaian isi, serta kesahan surat, (6) Penerusan surat pada bagian penyortir surat.

\section{METODE PENELITIAN}

Penelitian ini menggunakan pendekatan kualitatif. Pengumpulan data adalah dengan metode obervasi dan metode wawancara. Menurut Hasanah (2017), metode observasi merupakan proses pengamatan sistematis untuk menghasilkan fakta dari kegiatan yang berlangsung secara terus menerus dari aktivitas alami yang bertujuan untuk mendapatkan hasil secara fakta. Wawancara adalah metode pengumpulan data dengan mendapatkan informasi melalui pertanyaan, baik pertanyaan yang disiapkan maupun pertanyaan spontan (Sudaryati \& Permana, 2020)

Penelitian ini memaparkan data mengenai pengendalian internal untuk prosedur pengelolaan surat menyurat. Jenis data yang digunakan adalah data primer yang diperoleh peneliti selama Praktik Kerja Lapangan di kantor dinas tersebut. Data sekunder diperoleh peneliti dari evaluasi, dokumen, buku pencatatan, maupun arsip yang berkaitan dengan pengelolaan surat menyurat di Sub Bagian UMPEG Dinas Pariwisata Kepemudaan dan Olahraga Kabupaten Magelang.

Teknik pengumpulan data adalah teknik purposive sampling, yaitu teknik menentukan sampel dengan menentukan kriteria tertentu. Sumber data penelitian ini adalah informan yang berpengaruh dan dianggap memahami informasi dan permasalahan dalam kegiatan pengelolaan surat menyurat di Sub Bagian UMPEG. Informan dalam penelitian ini yaitu Kepala Sub Bagian UMPEG, staf UMPEG, dan Ka Sie 
Jurnal Manajemen dan Bisnis, Volume 2, No. 2, Januari 2021

Pemberdayaan dan Pengembangan Olahraga. Data yang diperoleh mengenai pengendalian internal, prosedur pengelolaan surat, pencatatan surat masuk dan surat keluar, faktor penghambat, serta solusi untuk mengatasi hambatan.

\section{HASIL PENELITIAN}

\section{Gambaran Umum}

Dinas Pariwisata Kepemudaan dan Olahraga merupakan instansi pemerintahan yang berada di Kabupaten Magelang. Kantor Dinas ini mempunyai tugas pokok yaitu melaksanakan sebagian urusan daerah pada bidang Pariwisata, Kepemudaan, dan Olahraga. Fungsi dinas ini adalah sebagai perumusan kebijakan teknis, penyelenggaraan, pembinaan, dan pelaksanaan tugas di bidang pariwisata, kepemudaan, dan olahraga. Pimpinan atau Kepala Dinas membawahi Sekretaris dan empat Kepala Bidang. Bidang tersebut meliputi Bidang Destinasi, Bidang Kepemudaan, Bidang Keolahragaan, dan bidang TIC (Tourist International Center). Sekretaris Dinas membawahi Sub Bagian Program, Sub Bagian Keuangan, dan Sub Bagian UMPEG. Kepala Sub Bagian UMPEG bertanggung jawab kepada Sekretaris Dinas. Salah satu tugas UMPEG adalah pelayanan administrasi dalam hal pengelolaan surat menyurat.

\section{Pengelolaan Surat Menyurat}

Pengelolaan surat menyurat baik itu surat masuk maupun surat keluar merupakan bagian penting dalam instansi pemerintahan. Pengelolaan surat di Kantor Dinas Pariwisata Kepemudaan dan Olahraga Kabupaten Magelang terbagi menjadi dua, yaitu pengelolaan surat masuk dan surat keluar. Sub Bagian Umum (UMPEG) merupakan unit pengelola surat baik surat masuk maupun surat keluar. Berdasarkan hasil observasi dan wawancara yang dilakukan, para pegawai Sub Bagian UMPEG sudah melaksanakan tugas sesuai tupoksinya. Hal ini sesuai dengan wawancara dengan Ibu Ita Kusmawati.AP selaku Kepala Sub Bagian UMPEG, yaitu:

"Iya pegawai sudah menjalankan tupoksinya masing-masing dan sesuai rencana."

Pengendalian internal pada Sub Bagian UMPEG dilakukan oleh Kepala Sub Bagian UMPEG. Agar terlaksananya pekerjaan yang baik, maka perlu adanya sistem pengendalian pada tata kelola organisasi. Perlu adanya pengarahan dan pengawasan pada kinerja pegawai. Peneliti menanyakan bagaimana pengendalian pada pelaksanaan tugas di bagian UMPEG. Hasil dari wawancara yaitu:

"Ada pengarahan dan pengawasan dari saya sebagai Ka Sub UMPEG. Sudah diarahkan sesuai tupoksinya dan setelah itu ada pengawasan dan pelaporan. Masing-masing staf menyampaikan laporannya dan ketika kita memiliki tugas langsung kita evaluasi, seperti itu."

Mengenai bagian pengelolaan surat, penulis menanyakan apa kesalahan yang pernah terjadi 
Jurnal Manajemen dan Bisnis, Volume 2, No. 2, Januari 2021

sehingga menimbulkan lemahnya pengendalian pada koordinasi dan komunikasi antar bidang. Menurut Ibu Ita Kusmawati.AP pada wawancara mengungkapkan tentang kesalahan pengelolaan sebagai berikut:

"Ketika itu petugasnya saja kurang teliti. Sebenarnya surat itu kan sudah turun dari atasan dan sudah ada disposisinya. Ya memang ada kesalahan dari pengelolanya atau mungkin pengelolanya sedang sakit dan sebagainya sehingga salah dalam kelola surat. Biasanya seperti itu."

\section{Prosedur Pengelolaan Surat Menyurat}

Setiap pengelola surat pada organisasi pemerintahan memerlukan pencatatan, pengelolaan, serta pendistribusian surat. Untuk kelancaran kegiatan pengelolaan surat dilakukan komunikasi dan penyampaian informasi mengemai surat kepada pihak yang dituju. Bentuk komunikasi kedinasan yang dilakukan sangat diperlukan agar prosedur pengelolaan surat menyurat berjalan efektif.

Prosedur pengelolaan surat pada Sub bagian UMPEG sudah cukup baik, meliputi penerimaan, pencatatan, pengagendaan, pengarahan dan pendistribusian surat masuk. Menurut Hidayat \& Jumiatun (2017), prosedur surat masuk meliputi tahap penerimaan, penyortiran, pencatatan, mengagendakan, pengarahan dan penerusan surat, penggandaan surat, dan penyimpanan surat. Dalam melaksanakan prosedur pengelolaan surat, peralatan yang digunakan yaitu buku agenda, lembar disposisi, dan stop map. Berdasarkan hasil wawancara dengan Bapak Muh Silauchudin selaku staf Sub Bagian UMPEG, prosedur pengelolaan surat masuk baik itu surat undangan maupun surat masuk biasa yaitu:

“Ada 2 surat masuk yaitu surat undangan dan surat masuk biasa. Prosedurnya, surat yang diterima kami catat ke buku agenda kemudian mengisi lembar disposisi, ditempel lalu direkomendasikan minta paraf ke Sekretaris Dinas. Setelah diparaf langsung dinaikkan ke Kepala Dinas. Turun lagi ke saya. Setelah itu nanti sesuai arahan dari Kepala Dinas turunnya di bidang mana, kemudian akan diteliti oleh sekretaris. Dari sekretaris kembali lagi ke saya, baru saya sebarkan surat itu ke masing-masing bidang atau istilahnya pemegang program itu."

\section{Kendala Prosedur Pengelolaan Surat Menyurat}

Hasil observasi dan wawancara diperoleh informasi yang menjelaskan kendala-kendala dalam prosedur pengelolaan surat menyurat. Pengelolaan surat di dinas terjadi kendala komunikasi dalam penyampaian atau ekspedisi surat dari pengelola surat ke bidang-bidang lain. Hal ini dijelaskan oleh Bapak Muh Silauchudin selaku staf Sub bagian UMPEG yaitu:

"Ada kalanya terjadi mis-komunikasi, contoh diantaranya nomor agenda, saya terkadang tidak menerima surat di meja saya, malah diletakkan di meja pegawai lain. Kemudian 
Jurnal Manajemen dan Bisnis, Volume 2, No. 2, Januari 2021

terkadang tidak jelas alamat tujuannya, surat yang diterima harus ditujukan ke bidang mana. Misalnya surat yang seharusnya ditujukan ke bidang Destinasi tapi malah di tujukan ke bidang TIC, karena memang alamatnya tidak jelas."

Penulis menanyakan bagaimana SDM pada bagian UMPEG khususnya di bagian surat menyurat. Hasil wawancara yaitu:

"Sebenarnya kurang, yang di bagian surat hanya saya. Terkadang banyak sekali surat yang harus dikelola, jadi saya kurang mampu. Baik itu surat undangan, surat masuk, surat keluar, buku telepon. Juga harus mengetahui nomor-nomor dinas yang ada di Magelang, itu juga harus dihafal walaupun itu sudah ada buku panduannya. Hal lain seperti kode-kode surat, karena jenis surat itu kodenya berbeda-beda. Jadi masih kurang."

Penilaian pada prosedur pengelolaan surat sangat penting demi terwujudnya sistem pengendalian yang baik. Penulis melakukan wawancara kepada Bidang Keolahragaan mengenai penyampaian surat yang menjadi tanggung jawab Sub Bagian Umum. Bidang Olahraga memberikan bahwa penilaian mengenai pengelolaan surat sudah berjalan baik. Terkadang terjadi konfirmasi yang jelas dari surat yang di terima. Hasil wawancara dengan Bapak Arif Rahman Hakim, S. Kom selaku Kepala Sie Pemberdayaan dan Pengembangan Olahraga yaitu:

"Pengelolaannya sudah baik, hanya saja kadang kurang komunikasi dan koordinasi yang jelas dari bagian surat dengan bidang olahraga, tapi tidak fatal juga. Kadang ada surat undangan yang seharusnya untuk besok tapi bidang kita belum menerima suratnya dan tidak tahau surat itu turunnya ke bidang mana karena disposisi dari atasan belum turun, jadi ya termasuk mendadak."

\section{Upaya Mengatasi Kendala}

Kegiatan pengelolaan surat menyurat di Sub Bagian UMPEG perlu adanya upaya untuk mengatasi kendala yang terjadi agar tercipta pengelolaan yang lebih optimal. Berdasarkan hasil penelitian, upaya yang dilakukan Sub Bagian UMPEG adalah lebih teliti lagi dalam penganganan surat. Hasil wawancara dengan Bapak Silauchudin selaku staf Sub bagian UMPEG yaitu:

"Saya harus lebih teliti lagi dan harus mencari benar-benar surat itu masuknya kemana. Meneliti buku catatan surat yang diterima di bidang destinasi apakah sama dengan catatan di buku saya, begitupun dengan bidang lainnya. Saya hanya harus mengoreksi agar tidak terjadi mis-komunikasi tersebut."

Dari hasil penelitian dapat dianalisis bahwa pengendalian pada Sub Bagian UMPEG yang masih perlu ditingkatkan. Perlu adanya upaya meningkatkan sistem pengendalian intern yang dapat menyelesaikan masalah prosedur pengelolaan surat menyurat pada Sub Bagian UMPEG. Hal tersebut akan berpengaruh pada ketepatan dan keefektifan dalam penyampaian 
Jurnal Manajemen dan Bisnis, Volume 2, No. 2, Januari 2021

informasi. Pengendalian intern perlu diperhatikan untuk mendukung pencapaian kinerja yang lebih baik.

Terdapat kendala dalam pengelolaan surat dan pendistribusian surat kepada bidang yang bersangkutan. Penanganan dan pengelolaan surat yang dilakukan adakalanya terjadi kesalahan terutama pada pengelolaan surat masuk. Kendala penanganan surat merupakan masalah utama dalam keutuhan informasi yang suatu saat akan dibutuhkan oleh suatu instansi karena surat tersebut mempunyai nilai yang sangat berharga, bisa sebagai bahan pembuktian atau bahan komunikasi yang menunjukkan kegiatan hidup atau dinamika suatu perusahaan yang bersangkutan (Dewi \& Octavia, 2018).

\section{KESIMPULAN}

Berdasarkan hasil penelitian dan pembahasan mengenai pengendalian internal untuk prosedur pengelolaan surat menyurat, penulis menyimpulkan bahwa para pelaksana Sub Bagian Umum sudah menjalankan tupoksinya sesuai tugas masing-masing. Kepala Sub Bagian Umum selain mengarahkan para pegawai juga melakukan pengawasan dan pelaporan. Pengelolaan surat di Sub Bagian Umum dan Kepegawaian sudah berjalan dengan baik. Kurangnya pegawai dalam bagian pengelolaan surat menjadi kendala yang ada di Sub Bagian UMPEG. Selain itu, kendala yang dihadapi adalah kurangnya komunikasi dan koordinasi antar bidang. Kendala tersebut diatasi dengan lebih teliti lagi dalam pencatatan dan distribusi surat kepada bidang yang bersangkutan.

Berdasarkan hasil penelitian pada "Pengendalian Internal Untuk Prosedur Pengelolaan Surat Menyurat Di Sub Bagian Umum dan Kepegawaian Dinas Pariwisata Kepemudaan dan Olahraga Kabupaten Magelang”, penulis memberikan saran pada penelitian selanjutnya yang terkait analisis yang dihasilkan. Pengembangan penelitian diharapkan mengkaji lebih luas referensi terkait pengendalian internal untuk prosedur pengelolaan surat menyurat memperluas data penelitian, Penelitian selanjutnya diharapkan dapat menggunakan metode kuantitatif untuk mendapatkan data yang lebih spesifik mengenai pengelolaan surat pada organisasi pemerintahan. Disarankan untuk meneliti sejauh mana tingkat pengendalian internal suatu organisasi pemerintahan dan pandangan pihak lain mengenai pengelolaan surat menyurat pada organisasi yang bersangkutan.

\section{DAFTAR PUSTAKA}

Dewi, D. P., \& Oktavia, L. (2018). Peran Sekretaris Dalam Mengelola Surat Masuk Dan Surat Keluar Pada Dinas Perpustakaan Dan Arsip Daerah Kota Tangerang Selatan. Jurnal Sekretari Universitas Pamulang, 4(2), 20.

Hakim, A. R. (2020, 23 Juni). Personal Interview.

Hakim, M. R., \& Mardiyah, S. U. (2017). PENGELOLAAN SURAT MASUK DAN SURAT KELUAR DI KANTOR KECAMATAN SENTOLO KULON PROGO. Jurnal Pendidikan Administrasi Perkantoran-S1, 6(4), 420-429. 
Jurnal Manajemen dan Bisnis, Volume 2, No. 2, Januari 2021

Halim, R. (2014). ANALISIS STRATEGI PENINGKATAN KINERJA BAGIAN SEKRETARIAT PADA DINAS PENDIDIKAN, PEMUDA DAN OLAHRAGA KABUPATEN BANGGAI. Academica, 6(1).

Hasanah, H. (2017). Teknik-teknik observasi (sebuah alternatif metode pengumpulan data kualitatif ilmu-ilmu sosial). At-Taqaddum, 8(1), 21-46.

Hidayat, S., \& Jumiatun, U. (2017). PROSEDUR PENGELOLAAN SURAT UNTUK MEMPERLANCAR PROSES PENYAMPAIAN INFORMASI PADA KANTOR KECAMATAN PAMULANG. Jurnal Sekretari Universitas Pamulang, 3(1), 33.

Ida Nuraida, S. (2008). Manajemen Administrasi Perkantoran. Yogyakarta: Kanisius.

Kanakan, P. M. (2002). Auditing. Edisi ke-6. Jakarta: SalembaEmpat.

Kusmawati, Ita. (2020, 23 Juni). Personal Interview. Kawan.

Marjo, Y. S. (2000). Surat-Surat Lengkap. Setia

Mukaromah, A., Nuraina, E., \& Suswandari, Y. (2013). ANALISIS SISTEM AKUNTANSI PERSEDIAAN OBAT-OBATAN UNTUK MENINGKATKAN EFEKTIVITAS PENGENDALIAN INTERN PADA RSUD KOTA MADIUN. THE 2nd FORUM ILMIAH PENDIDIKAN AKUNTANSI, 10.

Purwanto, D. (2006). Komunikasi Bisnis. Jakarta: Erlangga.

Rahardi, K. (2008). Surat menyurat dinas. Yogyakarta: Pustaka Book Publisher.

Ridha, M., \& Istiqomah, D. E. (2019). KUALITAS PELAYANAN DALAM PENGELOLAAN SURAT PD PASAR JAYA. Jurnal Administrasi Bisnis Terapan, 2(1).

Sedarmayanti. (2003). Tata Kearsipan Dengan Memanfaatkan Teknologi Modern. Bandung: Mandar Maju.

Silauchudin, Muh. (2020, 23 Juni). Personal Interview.

Sitohang, H. T. (2018). Sistem Informasi Pengagendaan Surat Berbasis Web Pada Pengadilan Tinggi Medan. Journal Of Informatic Pelita Nusantara, 3(1).

Sudaryati, E., \& Permana, T. D. (2020). ANALISIS PENERAPAN STANDAR AKUNTANSI PEMERINTAHAN BERBASIS AKRUAL PADA DINAS KEHUTANAN PROVINSI JAWA TIMUR. Berkala Akuntansi dan Keuangan Indonesia, 5(1), 1-13.
Sutarto. (1983). Sekretaris Dan Tata Warkat. Yogyakarta: Gadjah Mada University Press.

Widjaja, A. W. (1990). Administrasi Kearsipan

Suatu Pengantar. Jakarta: Rajawali Pers.

Widjajanto, N. (2001). Sistem Informasi Akuntansi. Jakarta: Erlangga.

Wursanto, I. (1991). Kearsipan. Kanisius.

Zulkifli, A. (1993). Manajemen Kearsipan. Jakarta: PT. Gramedia Pustaka Utama. 